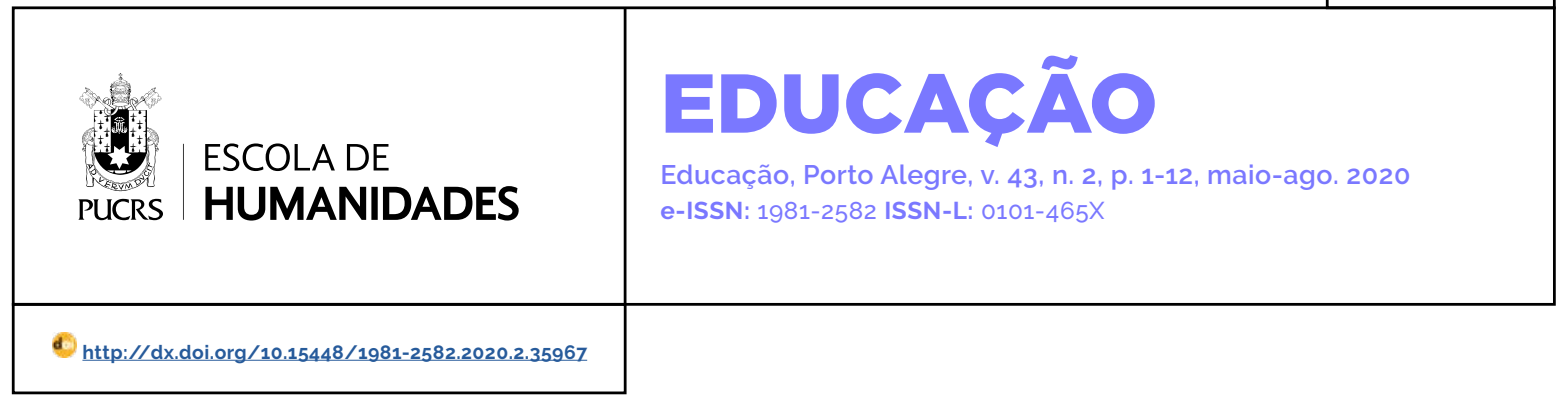

DOSSIÊ

\title{
El problema de la formación en la sociedad acelerada y la expropiación de la atención
}

O problema da formação na sociedade acelerada e na expropriação da atenção

The problem of education in the accelerated society and the expropriation of attention

António Gómez Ramos ${ }^{1}$

orcid.org/0000-0003-3823-7057

antonio.gomezramos@gmail.com

Recebido em: 11 out. 2019

Aprovado em: 26 mar. 2020.

Publicado em: 2 dez. 2020.
Resumen: La concepción clásica de la Bildung se construía sobre actividades culturales, sobre todo la de la lectura, que presuponian un grado alto de concentración, silencio y soledad, a partir de las cuales se esperaba producir una subjetividad reflexiva, autónoma y formada que era idealmente el sujeto de la Modernidad clásica. Los cambios tecnológicos y de hábitos sociales que se han producido paralelamente al orden neoliberal contemporáneo han erosionado ese tipo de actividades culturales, sobre todo la lectura, introduciendo un modo de vida acelerado y deudor de la inmediatez que, siguiendo a teóricos contemporáneos (Harmut Rosa, Jonathan Crary, Byung Chul Han) presentaremos como alienación. Sobre todo, la pérdida de la capacidad de atención y concentración, ligada al uso de las nuevas tecnologías, supone un reto para la Bildung clásica y obliga a una reformulación de esta.

Palabras clave: Bildung, atención, aceleración, lectura, sociedad disciplinaria, sociedad del rendimiento.

Resumo: O problema da formação na sociedade acelerada e na expropriação da atenção. A concepção clássica de Bildung foi construida sobre atividades culturais, sobretudo a leitura, que pressupunha um alto grau de concentração, silêncio e solidão, a partir dos quais se esperava produzir uma subjetividade reflexiva, autônoma e formada de acordo com o ideal de sujeito da Modernidade clássica. As mudanças tecnológicas e de hábitos sociais produzidos paralelamente à ordem neoliberal contemporânea têm deteriorado esses tipos de atividades culturais, sobretudo a leitura, introduzindo um modo de vida acelerado e devedor da imediatez que, de acordo com teóricos contemporâneos (Harmut Rosa, Jonathan Crary, Byung Chul Han), apresentaremos como alienação. Sobretudo, a perda da capacidade de atenção e concentração, relacionada ao uso das novas tecnologias, supõe um desafio para a Bildung clássica e obriga sua reformulação. Palavras-chave: Bildung, atenção, aceleração, leitura, sociedade disciplinar, sociedade do desempenho.

Abstract: The problem of education in the accelerated society and the expropriation of attention. The classical conception of Bildung was modelled on cultural activities, especially reading, which presupposed a high degree of concentration, silence and solitude; they were expected to produce a reflective, autonomous and formed subjectivity that was ideally the subject of classical Modernity. The technological changes and social habits that have taken place in the last decades, simultaneously to the contemporary neoliberal order have eroded this type of cultural activities, particularly reading, introducing an accelerated way of life that is dominated by immediacy and that, according to some contemporary theorists (Harmut Rosa, Jonathan Crary, Byung Chul Han) can be considered as a form of alienation. Above all, the loss of capacity for attention and concentration, linked to the use of new technologies, represents a challenge for classical Bildung and requires a reformulation of it.

Keywords: Bildung; attention; acceleration; reading, disciplinary society, achievement society. 


\section{A modo de introducción. Recuerdo del filósofo lector}

En un ensayo del año 1978, Georg Steiner (Steiner, 1997) recurria a un cuadro de Chardin, Le Philosoph lisant, para lamentarse de que EN la segunda mitad del siglo XX ya no se leía como en el siglo XVIII, cuando se pintó el cuadro. Ese óleo nos enseñaba todos los elementos que, según Steiner, iban aparejados a la lectura clásica, y que él desgranaba con fruición melancólica: la lujosa capa de piel y el sombrero con que se ha cubierto el filósofo para leer como si fuera a celebrar una ceremonia, el enorme tamaño del libro en formato de infolio, sin duda muy caro y objeto de lujo, el reloj de arena junto al lector, el silencio y concentración que se respiran, son para Steiner a la vez indice de la cortesía del lector para con su objeto libro, de la solemnidad del acto de lectura, y del hecho de que, seguramente, estaba releyendo el libro, más que leyéndolo. También el cálamo era significativo de que anotaba y escribía en el libro comentarios; sobre todo, de que lo transcribia y formaba parte de su memoria.

El tiempo era el elemento clave de la escena, como muestra el reloj de arena delante del libro y la calavera detrás del lector, en la estanteria. Se expresaban alli la vita brevis del lector frente a la ars longa del libro. Este iba a perdurar más allá de lector y de su tiempo, pues la palabra escrita es desde su invención una vía de eternidad; recuerda Steiner que ya Píndaro se solazaba en que "Cuando la ciudad que celebro haya muerto, cuando los hombres a quienes canto se hayan desvanecido en el olvido, mis palabras perdurarán." El tiempo y la palabra impresa, además, acaban por dictar justicia. Podriamos añadir en este punto al poeta español Francisco de Quevedo, quien en un soneto sobre la lectura ("Desde la torre") decía que la imprenta era "de injurias de los años vengadora", y le hacia justicia a los muertos. Por otro lado, las horas de lectura son las mejor empleadas en la propia vida y en la propia formación. Quevedo, remataba su soneto "En fuga irrevocable huye la hora/ pero aquella el mejor cálculo cuenta/ que en la lección y estudios nos mejora" (Quevedo, 1996, p. 98). Steiner recuerda con nostalgia cómo la lectura lenta, concentrada y solemne amueblaba de ecos y resonancias la mente del lector.

Hoy día, - esto es, a la altura de 1978 -, empieza a lamentarse Steiner, ya no se lee asi. Se lee rápido, en el metro o en el vestibulo del aeropuerto, en libros de bolsillo, libros que no se va a leer ya nunca más y que no son duraderos ni como objeto físico ni en el recuerdo de los lectores. Ya nadie sabe nada de memoria. La autoridad del autor ha desaparecido con todas las demás. El silencio no existe, ni tampoco la capacidad de atención, o la concentración que desaparece "por el simple hecho de que nos interrumpa el timbre del teléfono" (Steiner, 1997, p. 39) al que siempre contestamos. Los pequeños apartamentos modernos permiten acumular algunos libros de bolsillo en estanterías, pero no los libros encuadernados, menos aún los infolios de antes.

Las relaciones de poder, la economía del ocio y del servicio doméstico, la arquitectura del espacio privado y la custodia del silencio, que sostienen y rodean este acto, son más que inaceptables para los fines igualitarios de las sociedades de consumo occidentales (Steiner, 1997, p. 40).

Hay, desde luego, una componente de discutible nostalgia conservadora y elitista en el lamento de Steiner, que ya han abordado muchos críticos en varios lugares. La vamos a dejar de lado ahora. Para la discusión que voy a proponer sobre la posibilidad de la Bildung hoy, me interesa destacar dos puntos de este ensayo de Steiner.

Uno es esa escena de la lectura ligada a la soledad - una soledad solidaria en conversación con los ausentes -, al silencio, a la concentración, a la mejora de la propia persona por medio de este estudio, a la reflexividad que esa concentración y soledad conlleva; y sobre todo, la dimensión temporal por la que el lector llena de sentido su presente a través de la conexión y conversación con el pasado: aunque ilustrados con un cuadro del siglo XVIII, todos estos son los elementos de la Bildung que a partir del Romanticismo iba a ser el ideal definitorio y emancipador de la cultura moderna. Concentración, reflexión, autonomía, interioridad, juicio, etc.: con eso se 
formaba el sujeto moderno de la Bildung; en el límite histórico, la propia democracia se concebía como una sociedad de individuos racionales y razonables, esto es, gebildet, cultos y formados, que serían capaces de dialogar entre sí. Y es por esa Bildung clásica por la que Steiner entona un canto fúnebre en los inquietos años setenta del siglo XX, cuando los anhelos emancipatorios e igualitaristas del sesentaiocho todavía estaban vigentes; desde luego, antes de internet.

El segundo punto que quiero destacar es muy obvio. A la altura de la segunda década del siglo XXI, transcurridos veinticinco años de la revolución que han supuesto internet y todas las redes que van con ella asociadas -Google, Facebook, Twitter, etc.-, la nostalgia de Steiner parece, por un lado, desfasada y rancia, si es que no fuera de lugar. Pero, por otro, el contenido de esa nostalgia denuncia exactamente los mismos problemas estructurales a los que nos enfrentamos hoy cuando tratamos de definir el lugar y la posibilidad de la Bildung en la era internet. La aceleración de los tiempos, la pérdida de la capacidad de concentración, el ruido incesante que domina todos los ambientes, la confusión de presente y pasado, la disolución de la autoridad en el maremágnum de textos transmitidos y multiplicados instantáneamente por la red, el carácter efímero de los textos, la irreflexividad de los sujetos, la pérdida de la capacidad de juicio... todo esto, que Steiner vislumbraba con preocupación en la cultura del libro de bolsillo, se ha multiplicado en el mundo de hoy. No sería muy exagerado afirmar que el lector de libros de bolsillo en el metro de 1978 -al que Steiner mira con compasivo desprecioestaba más cerca del Philosoph lisant de Chardin que del sujeto atado hoy por sus ojos y sus auriculares a la pantalla de su teléfono celular o de su tablet; y que es justamente a él a quien de verdad le ocurre todo lo que Steiner criticaba en sus contemporáneos de los años setenta.

\section{La Red y la crisis de la lectura}

Sin duda alguna, estamos ante una ruptura epocal que parece implicar también un cambio antropológico, cuyas consecuencias todavía no somos capaces de calibrar ni de prever. Los sujetos que habiten este planeta en los próximos decenios van a ser constitutivamente muy distintos - en su estructura psíquica, en su modo de comunicarse entre sí, en su modo de percibir el mundo, de desear, de sentir y de razonar - de lo que era el filósofo lector del siglo XVIII o los mismos contemporáneos de Steiner en los setenta. De hecho, puede ser que el trato con internet produzca en ellos tales cambios cerebrales que incluso quien se formó todavía en el mundo de los libros y de la lectura en papel, de la escritura a mano - cualquier persona nacida hasta 1990 - haya experimentado en los últimos años una profunda metamorfosis cerebral, una vez que se ha habituado al manejo de internet.

Algo así afirma Nicholas Carr en su libro Superficiales. Lo que Internet está haciendo con nuestras cementes. (Carr, 2009). La maravillosa plasticidad de nuestras conexiones neuronales, que capacita a nuestros cerebros humanos adaptarse cada vez a nuevos entornos y aprender siempre cosas nuevas, ha permitido también que el antiguo lector, habituado de joven a concentrarse durante largas horas en las páginas de un libro, pueda ahora en su madurez distribuir su atención entre la pantalla que lee, las posibilidades ilimitadas de consulta que le ofrece el hipertexto, los correos electrónicos entrantes u otras notificaciones en el ordenador en el teléfono celular, más las muchas tareas que cualquier sujeto contemporáneo puede resolver simultáneamente: en suma, ha desarrollado una "mentalidad de malabarista" (Carr, 2009, p. 143) que es totalmente distinta de la atenta concentración con que, todavía en sus años de formación, podía quedarse fijado sobre un libro, sobre una idea, durante un periodo prolongado de tiempo. Pues la red "ofrece un tipo de estímulos sensoriales y cognoscitivos repetitivos, intensivos, interactivos, adictivos- que han demostrado capacidad de provocar alteraciones rápidas y profundas de los circuitos y las funciones cerebrales" (Carr, 2009, p.144).

El uso de internet habría producido nuevas conexiones sinápticas, o por decirlo coloquialmente, un "recableado del cerebro" que se manifiesta en 
todas las nuevas habilidades ligadas al "multitasking", y capacita asi para una lectura somera y superficial de los textos que van a apareciendo en la pantalla; pero, como contrapartida, argumenta Carr, "impide una lectura profunda" (CARR, 2009, p.152). Una larga serie de hallazgos empíricos de la neurología, asi como un cúmulo de experimentos psicológicos vienen a corroborar esta afirmación. En los lectores de libros, se activan las regiones cerebrales asociadas a la memoria, el lenguaje, o el procesamiento visual, pero no las regiones prefrontales asociadas a la adopción de decisiones y resolución de problemas. Asi, los lectores de hipertextos, y los de páginas web. van vagando de una página a otra, a golpe de clic, en lugar de leerlas con atención. Por decirlo sumariamente, las páginas web no se leen, sólo se visitan. En cierto modo, es natural, pues

tendemos a buscar situaciones que exigen actividades simultáneas o situaciones en las que nos abruma el volumen de información. Si el lento progreso de las palabras por la página impresa atempera nuestro afán de inundarnos de estímulos mentales, la Red lo fomenta. Nos devuelve a un estado natural de distracción irreflexiva, nos coloca ante infinidad de distracciones que jamás tentaron a nuestros antepasados (Carr, 2009, p.147).

Además, meticulosos experimentos psicológicos encuentran que este lector de internet, que ha pasado por muchas páginas en muy poco tiempo, o que ha leido un texto dejándose llevar por todos los vínculos hipertextuales que se le van ofreciendo, tiene muchas más dificultades que el lector tradicional para recordar y reconstruir lo que ha leido: dificultades, sobre todo, para reproducirlo en un relato. Esto es: con internet, habría entrado en crisis la propia capacidad narrativa, que en la Bildung tradicional es uno de los caracteres esenciales de lo humano (Bieri, 2012). Y porque este nuevo recableado impide la capacidad reflexiva de los sujetos, puede entrar en crisis la dimensión de interioridad y la capacidad para autoformarse con que la Bildung trataba de responder al mandato ilustrado de pensar por uno mismo (Koselleck, 2012). También las posibilidades de deliberación y diálogo que son la esencia de la democracia quedarian seriamente restringidas. En lugar de ello, tenemos un mundo de "fake news" transmitidas y recibidas aceleradamente y políticos populistas que se manifiestan a golpe de tweet.

Todo esto, como discutiremos enseguida, puede estar propiciado por, o ser el resultado de, una nueva estrategia adaptativa a las condiciones técnicas, materiales, de trabajo y de interacción social en el capitalismo más reciente. El multitasking, la toma rápida de decisiones, la superficialidad y la respuesta de sometimiento a un bombardeo incesante de estímulos es tanto una exigencia de las nuevas condiciones laborales como un requerimiento de la sociedad de consumo en la fase neoliberal del capitalismo. Así lo explicaría un análisis marxista en el que, de todos modos, Nicholas Carr no llega a entrar. Pero, sin necesidad de entrar en los fundamentos económicos y políticos de la red, la conclusión evidente es que ya no puede darse el lector lento y concentrado que hemos empezado dibujando con Steiner, pues "la red es un sistema de interrupción, y atrae nuestra atención para dispersarla" (Carr, 2009, p. 147).

\section{La sociedad acelerada y la sociedad del rendimiento}

Puede, entonces, que la pérdida de la capacidad de concentración y de atención, que la disminución del tiempo de reflexión y soledad corresponda a un cambio epocal. En tanto que la concentración, la soledad reflexiva y, desde luego, el tiempo, son elementos constitutivos de la Bildung moderna, será conveniente examinar brevemente en qué ha consistido ese cambio. Es un cambio que ha recibido muchos nombres y descripciones, según la perspectiva del autor que lo trate. Hay un acuerdo en que empieza a producirse en los años setenta del siglo XX, cuando la modernidad clásica llega a su límite, y justo cuando Steiner lanza su elegía por la (entonces solo supuesta) decadencia de la lectura. A lo que vino después, algunos lo llamaron postmodernidad - una categoría que hizo furor 
en las últimas décadas del XX y que hoy ya solo permanecería como categoria estética, más que histórica o política: en lo último, se correspondería con el más que discutible fin de la historia. Otros han preferido hablar de una nueva fase de la modernidad, en la que esta se habría radicalizado, o se habría hecho más reflexiva, más consciente de si misma, de sus propios limites y posibilidades. Geográficamente, esta nueva época, que corresponde a los últimos cuarenta años, ha consistido en una globalización en todos los aspectos de la vida, una globalización intensiva, irreversible y cargada de contradicciones. Historiográficamente, se ha hablado de una desaparición del futuro, o de una extensión indefinida del presente, un presente lento o un tiempo estancado (Gumbrecht, 2011; Cruz, 2017). Política y económicamente, ha supuesto la expansión del llamado neoliberalismo a escala planetaria, imponiendo unas formas de producción, comunicación y consumo sometidas al patrón de la inmediatez, que corresponden muy bien a lo que hemos empezado a describir en la sección anterior (Gomez Ramos, 2013). También, es cierto, ha impuesto un aumento de la desigualdad y un recrudecimiento de la explotación laboral que no pueden ser objeto de análisis aqui, pero que, probablemente, no dejan de tener relación con las nuevas formas de consumo. También una nueva forma de Bildung tendría que dar cuenta de ellas.

Harmut Rosa (2016) ha puesto el énfasis en que lo más característico de este nuevo giro epocal es la aceleración: una aceleración de los procesos sociales y los tiempos vitales que coincide, paradójicamente, con un estancamiento del tiempo histórico. En el diagnóstico de Rosa, esta aceleración resulta incompatible con las condiciones humanas para una vida buena, una vida lograda; por ello, la aceleración conlleva una alienación, término que él propone recuperar de la filosofia clásica. A la vez que nos sometemos voluntariamente a un ritmo de vida que en realidad no quisiéramos, se hace imposible realizarse como ser humano en las condiciones de aceleración de los tiempos a las que nos somete el presente neoliberal. La precarización de la vida laboral y la consecuente "corrosión del carácter" (Sennet, 1998) que este conlleva, la casi total imposibilidad de forjarse un plan de vida, amenazan con destruir la construcción de una subjetividad coherente. Con respecto a la Bildung, la conexión es aqui manifiesta, y ha sido ya remarcada por muchos autores y críticos del ritmo educativo que impone la ideología neoliberal: la formación requiere tiempo fuera del tiempo, lentitud para la maduración, toda una serie de procesos maduración e incluso de vías muertas que la obsesión neoliberal por el rendimiento inmediato no puede tolerar.

Para los propósitos de este texto, no obstante, y habiendo partido de la crisis de la lectura -o del cambio en los modos de lectura- que introducia el texto de Steiner, centraremos nuestra discusión en el tiempo y la atención: sin duda, son los dos aspectos que han experimentado un cambio más visible y empíricamente comprobable en nuestra época.

El filósofo coreano alemán Byung-Chul Han (Han, 2012) vislumbra a la base de esos cambios una transformación sociopolítica, quizá una transformación psicopolítica. En su diagnóstico, el paso de la modernidad clásica a esta nueva modernidad debe describirse como el final de la sociedad disciplinaria de Foucault y su relevo por lo que él llama la sociedad del rendimiento. Foucault enseñó de modo muy convincente que lo propio de la modernidad clásica, desde el siglo XVIII, XIX y XX - no lo olvidemos: durante la época de la Bildung - era un régimen disciplinario y de control (Foucault, 1986). Una arquitectura de muros y opacidad que se reproducía por igual en las escuelas, los hospitales y las cárceles; unos sujetos de obediencia sometidos al mandato de la ley, a la autoridad del padre, a la culpa y al "Tú debes". Una sociedad que sólo incluía a los que eran capaces de someterse y que condenaba a los incapaces a la exclusión de la locura y del crimen: a la cárcel y al manicomio iban los que no habian sido capaces de adaptarse a la disciplina de la escuela y de la fábrica.

Una sociedad, también, de disciplinamiento del tiempo, que diferenciaba estrictamente los tiempos de trabajo y los de ocio, los días de la semana 
y el domingo, los dias de fiesta. Pero esta sociedad disciplinaria, que se articulaba políticamente en los Estados nacionales modernos (ya fueran democráticos o totalitarios), que se expresaba en el arte de las vanguardias, que podia encontrar en Kafka su autor paradigmático, ha ido dando paso, según Byung Chul Han, - conforme se expandia el orden neoliberal - a una arquitectura de cristales transparentes que se reproduce de modo similar en aeropuertos, bancos, centros comerciales y gimnasios - también en algunas universidades de reciente construcción-. Con esta transparencia - en realidad, una transparencia aparente- llega una desregulación generalizada, no solo en la economía, sino en todos los órdenes de la vida. En el orden del tiempo, donde desaparece la distinción entre los dias festivos y los de trabajo, o las horas de descanso y las de labor: la producción y el consumo tienen lugar veinticuatro horas al día, siete dias a la semana (Crary, 2015). También se desregula la moral y el comportamiento cotidiano. En el sexo, en la vestimenta, en el trato intersubjetivo, prácticamente nada está prohibido, o todo está permitido. Frente a la negatividad del mundo moderno, esta desregulación prima la positividad, expresada de nuevo en todos los ámbitos de la vida, también en esa exhortación cotidiana al pensamiento positivo. Si en la sociedad disciplinaria primaba el "Tú debes" kantiano, ahora parece no haber mandamientos; tan solo la exhortación única de "Tú puedes": no tienes nada que obedecer, pues no hay autoridad externa que imparta órdenes; solo tienes que rendir hasta el máximo de tus posibilidades, que no tienen más límites que las que tú pongas. Tus fracasos, por tanto, serán tu propia responsabilidad. La sociedad disciplinaria queda entonces sustituida por la sociedad del rendimiento. Los sujetos se constituyen sobre el mandato de rendir, de sacar la máxima productividad de si mismos en un entorno que ofrece infinitas posibilidades en lo tecnológico, en lo moral, en lo vital. El foucaultiano sujeto de obediencia moderno (que era, en cierto modo, la cara negativa del sujeto de la Bildung) ha dado paso al sujeto del rendimiento.
Evidentemente, como Han hace notar, y la observación cotidiana en las sociedades occidentales contemporáneas pone de manifiesto, este sujeto del rendimiento es un sujeto auto explotado - aparentemente autónomo, declarado empresario y jefe de si mismo -, que no puede conocer el descanso ni el reposo, ya solo por el hecho de estar, de tener que estar, conectado permanentemente. Más que una aceleración tal como la describia Rosa, lo que padece es una disincronía, una dispersión temporal. El tiempo carece de ritmo ordenador, va dando tumbos sin rumbo alguno. Como no hay limite a lo que puede, no puede tampoco conocer la gratificación, y vive en una insatisfacción y ansiedad permanente. Vive lanzado hacia sus objetivos de rendimiento: objetivos de lo que puede, y por tanto debe producir, del dinero que puede, y por tanto debe ganar, pero también de las experiencias que puede llegar a tener, las cosas que debe probar, los paises que puede visitar. Sartre, y en parte Heidegger, caracterizaban al sujeto moderno como "proyecto". Pero, apostilla Han, el sujeto del rendimiento, más que un proyecto, es un "proyectil". Puesto que no hay prohibiciones, es dificil que se convierta en un loco o en un criminal: los dos tipos de excluidos que no se sometian a la prohibición; pero sí es muy posible que termine quemado, burnt-out, eliminado de la carrera laboral y orillado en los márgenes de la vida por agotamiento. Las estadisticas lo confirman: la depresión, y el burnt-out son hoy una auténtica epidemia planetaria.

Los análisis sociales y politicos mínimamente criticos del presente muestran que, no obstante, el diagnóstico de Byung Chul Han, la sociedad disciplinaria descrita por Foucault sigue teniendo vigencia. A pesar de sus discursos de transparencia y positividad, el orden neoliberal no se ha flexibilizado en ninguna de las líneas centrales de su sistema de dominación, recurre a la represión cuando es preciso y se sostiene sobre la exclusión que produce. Ni ha disminuido el gasto militar, ni han dejado de existir las prisiones -que si que han modificado su arquitectura y se han desplazado del centro de las ciudades-; la marginación de 
amplias capas de la población ha sustituido a la antigua exclusión, y la apertura de fronteras que la globalización requiere va paradójicamente acompañada de muros físicos y dispositivos de control fronterizo cuyos deliberados efectos mortales se rebelan cada día en el Mediterráneo o en el paso entre México y los Estados Unidos. El orden neoliberal contemporáneo no deja de asentarse sobre un disciplinamiento violento. Sin embargo, en su discurso en "positivo" sobre la formación de los sujetos, en su exhortación al rendimiento y al aprovechamiento ilimitado de todos los ámbitos de la vida, en el trabajo y en el ocio entendido como consumo, en los espacios que propicia para que los individuos aparentemente integrados, no excluidos, den el máximo de sí y, efectivamente, acaben quemándose, el análisis de Byung Chul Han parece certero. Cuando se trata de la formación de los sujetos, del acceso de estos al conocimiento y a la información, de los modos de procesarla en la relación consigo mismos y con los otros, son los patrones descritos de la sociedad del rendimiento los que dominan hoy el discurso teórico y práctico.

En tanto que los sistemas educativos y los dispositivos ideológicos apuntan a este sujeto del rendimiento, y el propio entorno tecnológico en que se desenvuelve también lo hace, nos debemos preguntar, entonces, por la posibilidad de una Bildung en estas condiciones de rendimiento, de mandato de positividad y de logro. ¿Cuáles son las posibilidades de formación, de educación de la propia subjetividad en estas condiciones de la sociedad acelerada y del rendimiento?

\section{La psique desasosegada}

Retornemos ahora al contraste con el Philosoph lisant de Chardin, y al fenómeno de la lectura, al acto material mismo de la lectura. Pues lo que el entorno tecnológico actual, el orden socio-económico y los hábitos asociados a él propician como lectura, como relación con los signos y el conocimiento, es necesariamente muy distinto de la lectura clásica que Steiner describía nostálgicamente. Steiner acusaba la falta de ceremoniosidad, la informalidad de leer un libro de bolsillo en un momento casual, frente a la solemnidad del acto de leer en el cuadro de Chardin. Pero lo que él describe como falta de etiqueta apunta a algo más profundo y más grave.

Lo característico de esta sociedad del rendimiento, del exceso de positividad, o visto desde la dimensión temporal, de esta inmediatez, es la sobrecarga de estímulos y la aceleración con que se plantean y se resuelven -se tienen que resolver- las tareas (Rosa, 2009; Han, 2012). La tendencia al multitasking, que los sujetos ejecutan desde la infancia hasta la edad adulta, provoca una dispersión y fragmentación de la atención que se manifiesta en la propagación, casi epidémica, del llamado sindrome de déficit de la atención e hiperactividad o TDAH, particularmente extendido entre los niños y los jóvenes. Ciertamente, como han señalado algunos críticos (García, González, Pérez, 2014), este síndrome es menos el diagnóstico de una patología real que señala hacia nuevas formas de comportamiento dificiles de catalogar, las cuales no se deberian patologizar de modo automático. Pero, sea o no una enfermedad, da muestra de un cambio en los procesos cognitivos y perceptivos de los sujetos actuales frente a los de la modernidad clásica de la Bildung. Puede incluso, como afirman algunos, que se esté produciendo un cambio psíquico tan drástico como el que supuso la invención de la escritura hace diez mil años.

Byng Chul Han lo expresa en el contraste entre la capacidad contemplativa humana y la actividad frenética a la que se ven abocados los sujetos de hoy, ya desde la infancia, que les hace incapaces de mirar, de escuchar, de leer, o simplemente de aburrirse. Ya casi nadie parece capaz de mirar como miraba Cezanne, quien, según Merleau Ponty,

Al comienzo, trataba de hacerse una idea de los estratos geológicos. Después, ya no se movia más de su lugar y se limitaba a mirar, hasta que sus ojos, como decía Madame Cézanne. se le salían de la cabeza. [...] El paisaje. remarcaba él, se piensa en mí: yo soy su consciencia (Han, 2012, p.38).

Este limitarse a mirar, sin moverse del lugar, de manera que el propio yo queda indiferenciado del objeto al que mira es lo que, de un modo aun no 
suficientemente explicado, se ha llamado "atención". Lo primero que caracteriza a la atención, cuando se contempla exteriormente al sujeto atento, es su capacidad para ofrecer resistencia a los estímulos externos, para mantenerse fijado en un objeto sin dejarse llevar por otra estimulación distinta. Mientras que ese dejarse una persona llevar y traer por el bombardeo de sensaciones exteriores es lo que, a su vez, la convierte en un ser desasosegado, sometido a una actividad frenética que él no determina. Tampoco es una novedad de nuestro mundo tardo moderno. Ya Nietzsche, el gran crítico del siglo XIX, lo expresaba diciendo que

por falta de sosiego, nuestra civilización lleva camino de desembocar en una nueva barbarie. En ninguna época se han cotizado tanto los activos, es decir, los desasosegados. Cuéntanse, por tanto, entre las correcciones necesarias que deben hacérsele al carácter de la humanidad el fortalecimiento en amplia medida del elemento contemplativo (Nietzsche, 1988, p. 232).

Y, ciertamente, en la Modernidad más temprana, como han mostrado reiteradamente Koselleck o Harmut Rosa (Koselleck, 2000; Rosa, 2009), por ejemplo, se daba con frecuencia la queja por el frenesí y la aceleración de los tiempos, que impiden la contemplación. En ese sentido, la época que estamos aquí analizando como sociedad del rendimiento o sociedad acelerada debe ser considerada como una radicalización de la modernidad, más que una ruptura sobre ella. Lo que se radicaliza es, como veíamos más arriba, la aceleración de los procesos vitales y sociales. En la vida cotidiana, y sosteniéndose ahora en el inmenso cambio tecnológico que han traído los ordenadores, internet, las comunicaciones cibernéticas, la proliferación de la imagen y de lo visual, esa aceleración ha supuesto una multiplicación de las tareas a realizar por los individuos en un tiempo muy corto -de ahí el multitasking - y una sobreestimulación perceptiva que reclama un cambio continuo en la mirada y en el oído sobre todo; en cualquier caso, un cambio continuo en el foco de atención. Si el mandato laboral, económico, social, es "no te pares, muévete, emprende siempre algo, tienes que estar siempre activo", el entorno perceptivo y tecnológico favorecen ese movimiento continuo y esa exhortación a la "actividad".

Ciertamente, corrige Han, esta "actividad" es más bien una pasividad, toda vez que el individuo se ve llevado y traído sin autonomía alguna de un estímulo a otro, de una tarea a otra, y su frenesí no es acción, sino el movimiento agotador y estéril del hámster en la rueda. Ya en el mismo acto de lectura, del que hemos partido, se puede afirmar que la actividad psíquica del lector atento que lee continuadamente un solo texto -ya sea el philosoph lisant de Chardin o el lector de libros de bolsillo- es mucho más intensa que la de quien salta agitadamente de una website a otra, respondiendo de modo reflejo, pero sin reflexión, a los estímulos que aparecen en la pantalla, los cuales le ofrecen la pequeña satisfacción inmediata de una nueva información. La ilusión de omnipotencia que produce el leve toque del dedo en el ratón o en la pantalla digital esconde una sujeción a la satisfacción veloz y una ausencia de autonomía.

Para un estudio sobre la posibilidad actual de la Bildung, sobre las vías educativas del presente, seria, sin duda, imprescindible detenerse en esta pérdida de autonomía del sujeto lector: la conversión del lector quieto que interpreta activamente en un agitado internauta sometido pasivamente a un esquema de estímulo visual o sonoro-respuesta táctil. La autonomía del lector frente a la heteronomía del internauta. Esto llevaria a un estudio más amplio y profundo. Nuestra hipótesis aquí, sin embargo, es que la escena material de la lectura (la del libro frente a la de la pantalla de ordenador, por ejemplo) no es tan decisiva como la capacidad de atención y contemplación que se pone en juego en esas escenas y que, como sugeria Byung Chul Han a propósito de Cezanne o de Nietzsche, se pierde peligrosamente en la tarda modernidad de la sociedad del rendimiento.

\section{La atención y la Bildung}

El problema, pues, está en la atención, y en su pérdida. Un invitado en un programa de televisión no debe hablar más de cuarenta segundos seguidos, se dice, porque transcurrido 
ese tiempo el telespectador cambiará de canal, en busca de otra imagen y otro discurso. Pues pocos pueden escuchar durante un rato largo. El cine, a su vez, requiere imágenes rápidas, muy dinámicas, evitando los planos fijos. ${ }^{2}$ Las consecuencias sociales, políticas, o morales de esto se han hecho ver. Si no es posible hacer en público un argumento prolongado, que lleve varios minutos y demande un esfuerzo de atención, la democracia se resiente. Como he venido sugiriendo, en la Modernidad clásica, sin realizarse nunca de modo efectivo, pero siempre como promesa y supuesto, más al alcance de las clases dominantes que de las masas, funcionaba una ecuación por la que el adiestramiento en la lectura concentrada, la capacidad de escucha (particularmente, la escucha de música clásica), propiciaban una reflexividad y una autonomía personales que, a su vez, capacitaban para la acción política, la vida pública y la ciudadanía.

En las sociedades occidentales actuales, el grito, o el tweet, o la noticia impactante pero falsa, las "fake news" determinan el curso de los acontecimientos y las decisiones colectivas mucho más que la discusión racional. La democracia requiere tiempo y atención. También lo requiere la moral, el cuidado del otro y la sensibilidad y atención hacia su necesidad y precariedad. Por eso, también la moral está en juego. Y, como resultado, está en cuestión la posibilidad misma de formarse como sujeto, de constituirse hasta pensar por sí mismo y tener juicio propio, que exige autodisciplina y una paciencia.

Parte de esta autodisciplina, apostilla aún Han en un giro que hubiera sorprendido a los teóricos clásicos de la Bildung, estaba en la capacidad de aburrimiento. La cultura, escribe

requiere un entorno en el que sea posible una atención profunda. Esta es ahora reemplazada cada vez más por una atención por completo distinta, la hiperatención. Esta atención dispersa se caracteriza por un acelerado cambio de foco entre diferentes tareas, fuentes de información y procesos. Dada, además, su escasa tolerancia al hastio, tampoco admite aquel aburrimiento profundo que seria de cierta importancia para el proceso creativo (Han, 2012, p.38).

No en vano, la sociedad del rendimiento es también una sociedad del entretenimiento, que garantiza que ningún minuto del ciudadano-consumidor esté vacio de ofertas, desocupado, quizá justamente para compensar esa sensación de tedio, hastio y aburrimiento que, como muestran varios estudios, es también un fenómeno típicamente moderno, que no se conocía apenas antes del siglo XVIII (Dalle Pezze, Salzani, 2009). La infra estimulación, el vaciado del mundo que se da en el momento del aburrimiento debe compensarse con esa sobreexcitación que la modernidad ha tendido a producir y que en la actualidad es casi la norma diaria. Ya nadie es capaz de aburrirse porque siempre tiene a su disposición algo con lo que entretenerse: es casi imposible encontrar a alguien mirando al vacio mientras espera en la parada de autobús, pues ese momento de espera se llena inmediatamente con el teléfono celular o con los estímulos publicitarios del entorno urbano. Sin embargo, ese momento de vaciedad y de aburrimiento, puede ser, para Walter Benjamin, en su ensayo sobre "El narrador", un momento de la creación, pues, "[Alasí como el sueño es el punto álgido de la relajación corporal, el aburrimiento lo es de la relajación espiritual. El aburrimiento es el pájaro de sueño que incuba el huevo de la experiencia" (Benjamin, 1977, p.446).

O bien, para Heidegger, el aburrimiento profundo es uno de los momentos culminantes de la existencia, donde el Dasein se descubre a sí mismo, se encuentra con su yo y con sus deseos. Quizá por eso, se pregunta él en su curso sobre los Conceptos fundamentales de metafísica, "el hombre moderno se ha vuelto aburrido para si mismo porque no reconoce, no es capaz de reconocer ese aburrimiento profundo?" (Heidegger, 1983, p.240). El carácter formativo y creador del aburrimiento se pierde definitivamente en un sujeto permanentemente entretenido.

\footnotetext{
2 Por supuesto, hay movimientos estéticos en contra, para compensar esto: cine de autor, la obra de John Cage y Morton Feldmann en música, todas las tendencias slow que se ofrecen en la sociedad contemporánea. Pero parece claro que se trata de movimientos de compensación frente a una corriente dominante.
} 
En todo caso, esta incapacidad contemporánea para el aburrimiento -que supone, sin duda, un serio obstáculo a métodos más clásicos de aprendizaje- puede ser considerada dentro del marco socioeconómico de la atención, la distracción y el entretenimiento. O, por decirlo con las palabras de Jonathan Crary, resulta de una nueva economía de la atención que viene impuesta en el orden neoliberal. La tesis de Crary (Crary, 2001) es que, puesto que el modo de mirar y de percibir está determinado culturalmente, esto es, no es un mero proceso fisiológico natural, sino que tiene una historia, se hace preciso estudiar cómo ha modelado la Modernidad el modo de mirar. De hecho, tal como muestra él, el arte ha cumplido un importante papel en este sentido, y la evolución de la pintura en el siglo XIX no puede entenderse fuera de los marcos de percepción definidos por la sociedad industrial capitalista. Esta, a la vez que determinaba los modos de trabajar, de consumir o de habitar, y con ello modelaba a los individuos, también les educaba en una cierta mirada. En última instancia, les exigía que se definiesen en función de cómo "prestan atención". La Bildung clásica también jugaba un papel en este sentido.

El giro de la modernidad clásica a la sociedad acelerada de la que venimos hablando tiene lugar porque, de manera creciente, la sociedad moderna somete a los individuos a un bombardeo de estímulos tan grande que exige una atención dispersa, y un aparato perceptivo capaz de distraerse, o incapaz de una atención fija y constante. En otras palabras, se ha pasado del observador pasivo, distante que contemplaba un cuadro en un museo y quizá emitía un juicio sobre él, a un sujeto de atención inestable, que salta de una imagen a otra, de una información a otra, con la rapidez y habilidad que hemos descrito antes y que tanto su trabajo como su ocio le requieren, pero que ya no puede mirar o concentrarse en algo durante un tiempo prolongado.

En suma, ha tenido lugar una poderosísima transformación social del observador. En las condiciones de la cultura actual se dan y se imponen nuevas estrategias de subjetivación que no discurren ya de modo predominante en el observador de una pintura, o en el lector de un libro, sino en una sujeción a un torrente de potentes estímulos externos que van atrayendo y exigiendo la atención. Como ese torrente de estímulos, sobre todo en la pantalla, no es tampoco casual, sino que está dirigido de una u otra manera, a veces impersonalmente, pero siempre dentro de las dinámicas de trabajo y consumo, Crary puede concluir que la expropiación de la atención es la forma capitalista contemporánea de alienación. Los individuos de lo que hemos llamado la sociedad del rendimiento viven con la atención secuestrada. Si en las fases primeras de la modernidad capitalista el trabajador se veía desposeído de su cuerpo y de su tiempo sin saberlo; si la industria cultural posterior, tal como la analizaba la Escuela de Frankfurt, le despojaba también de su ocio e incluso de su inconsciente, el paso último, en esta época de internet y de comunicación inmediata y globalizada, ha sido la expropiación de la atención: es otra instancia ajena al individuo la que determina de manera continua dónde pone este sus ojos y sus oidos, a dónde dirige la mirada y, además, controla constantemente cómo tiene eso lugar. Visto así, despojado de su capacidad de atención, permanentemente distraído, este individuo tardo moderno podrá estar dotado en principio de todas las libertades políticas, estéticas, morales e incluso físicas y corporales para configurar su vida, pero no es dueño de sí mismo, si es verdad que la atención es lo que en última instancia define a un sujeto. El control de la propia atención, de hacia dónde enfoca un sujeto su energía psíquica y su sistema perceptivo es, al fin y al cabo, el grado cero de la autonomía individual.

El valor de la atención y su tensión con la distracción ha estado presente, a menudo como un conflicto normativo, en la historia de la filosofía al menos desde Platón. En cierto modo, este venía a apreciar la atención con la que se contemplan las ideas por encima de las distracciones que las sombras ofrecen a los prisioneros de la caverna; la distracción era para Descartes causa del error que se comete por no seguir atentamente el método, o era para Pascal "nuestra mayor miseria, pues 
son el principal obstáculo para pensar en nosotros mismos, y nos llevan a la depravación." (Pascal, 1981, p.126). Es "la verdadera oración natural por la que accedemos a lo que la razón nos ilumina", apostillaba Malebranche (Löffler, 2014, p. 37). Se condenaba así la diáspora, la disipación que era lo contrario del recogimiento y la concentración.

En cambio, Montaigne celebraba la distracción como "médico supremo de nuestras pasiones" (Montaigne, 2007, p. 1048), pues la variación alivia, disuelve y diluye. Y Kant recomendaba una "dietética del alma", una técnica que consiste en distraerse, "desviar la atención (abstractio) desde ciertas ideas dominantes, repartiéndolas en otras distintas" (Kant, 1964, p. 518) para asi reunir fuerzas y seguir trabajando luego, con la atención reforzada.

Como puede verse, los frentes de esta discusión están curiosamente cruzados. Todavía en el siglo XX, Simone Weil se convierte en la valedora de la atención, a la que atribuye un enorme valor moral:

La atención consiste en suspender el pensamiento, en dejarlo disponible, vacio y penetrable al objeto, manteniendo cerca del pensamiento [...], los diversos conocimientos adquiridos que deban ser utilizados [...]. Y sobre todo el pensamiento debe estar vacío, a la espera, sin buscar nada, pero dispuesto a recibir en su verdad desnuda el objeto que va a penetrar en él (WEIL, 1988, p.260).

En cambio, Walter Benjamin, a quien veiamos reivindicando la necesidad del aburrimiento y que inspiraba en gran parte las concepciones de Jonahtan Crary sobre la determinación tecnológica y económica del sistema perceptivo, fue el primero en apreciar sistemáticamente la influencia del cine en el modo de mirar y percibir. Su ensayo sobre "La obra de arte en la época de su reproductibilidad técnica" (Benjamin, 1977) estaba imbuido de un ambiguo optimismo histórico; buscando las posibilidades emancipadoras del cine, Benjamin podia apreciar en este arte, entonces muy reciente, una nueva forma de percepción: la "percepción distraida", o la "percepción en la distracción (Wahrnehmung in der Zersteuung)" con que las masas trabajadoras se acercaban a las salas de cine. Frente al "recogimiento" y "devoción" preconizado por el arte burgués, la masa disipada, distraída, "sumerge la obra de arte en si", la toca, más que la ve y, desde un sistema perceptivo distinto a la estética clásica, puede juzgar, esperaba Benjamin, de una manera nueva y liberadora. Por eso confiaba en el cine como el gran arte revolucionario, donde la estética se hacía política.

El tiempo no ha dado la razón al optimismo de Benjamin, y la poderosa tecnología de la imagen móvil ha propiciado más bien una forma más profunda de alienación, como sugiere Crary. No obstante, los términos del debate entre atención y distracción parecen ser decisivos para cualquier reformulación de la idea de Bildung en un mundo modelado por el orden neoliberal y las nuevas tecnologías. Tal como he sugerido, ese mundo hace ya inviable, y seguramente innecesaria desde el punto de vista económico y político, la realización de una Bildung clásica que empezábamos describiendo en el acto de lectura del Philosoph Lisant de Chardin. Era una Bildung que se pretendía universalmente emancipadora, pero que fue históricamente deudora de un orden socio-cultural jerarquizado; en sus pensadores clásicos, se "proponía como una Bildung despolitizada, ignorando la realidad" (Mas, 2010, p.49), pues, a pesar de sus origenes ilustrados, fue hasta cierto punto cómplice de una sociedad disciplinaria. El orden actual, que aqui hemos caracterizado, con matices, como una sociedad del rendimiento, disuelve aparentemente esa disciplina, e incluso promete un acceso universal al conocimiento - de hecho técnica, materialmente, hace realizable esa promesa -; pero instaura a la vez un control tan intenso de la atención y de los movimientos psiquicos que hace imposible la autonomía, la reflexión y el grado de conciencia que eran objetivos de la Bildung.

Probablemente, no podremos evitar que nuestro aparato perceptivo futuro sea distinto del lector, del observador, del oyente clásico que ha sido el protagonista de la formación cultural durante los últimos tres siglos. Apenas seremos capaces de concentrarnos en una lectura durante unas horas sin atender a un mensaje del teléfono celular o a una notificación en la pantalla, pero seremos muy duchos en la multitarea, repartire- 
mos nuestra atención entre objetos diferentes, en espacios de tiempo cada vez más breves. La cuestión será si en esta nueva habilidad hay autonomia y reflexión, o si tendremos toda nuestra atención alienada. Tal vez, aprender a leer, mirar y pensar a la vez, y también a parar de hacer lo uno o lo otro seria la Bildung. Definir esto es, sin duda, una de las labores decisivas en cualquier teoría de la educación de hoy.

\section{REFERENCIAS}

Benjamin, W. (1977). Gesammelte Schriften (Bd. II/2). Franfurt: Suhrkamp

Bieri, P.(2012). Wie wäre es, gebildet zu sein. In H. Hastedt (Ed.), Was ist Bildung. Eine Textantologie. Reklam: Stuttgart.

Carr, N. G. (2009). Superficiales. ¿Qué está haciendo internet con nuestras mentes? Madrid: Taurus.

Crary, J. (2015). 24/7 Capitalismo tardio y el fin del sueño. Barcelona: Ariel.

Crary, J. (2001). Suspension of Perception. Attention, Spectacle and Modern Culture. Massachusets: MIT.

Cruz, M. (2017). La flecha (sin blanco) de la historia. Barcelona: Anagrama.

Dalle Pezze, G., Salzani, C. (Eds.). (2009). Essays on Boredom and Modernity, New York: Rodopi.

Foucault, M. (1986). Vigilar y castigar. Buenos Aires: Siglo XXI.

Garcia F., González H., Pérez Álvarez, M. Volviendo a la Normalidad. La Invención del TDAH y del Trastorno Bipolar Infantil. Madrid: Alianza Editorial, 2014.

Gomez Ramos, A. (2013). La inmediatez de la crisis y la experiencia del tiempo. In L Cadahia y G. Velasco (Eds.), Crisis de la normalidad. Normalidad de la crisis (pp. 101-122). Madrid: Katz.

Gumbrecht, H.U. (2011). Lento presente. Madrid: Escolar y Mayo.

Han, B. Ch. (2012). La sociedad del cansancio. Barcelona: Herder.

Heidegger, M. (1983). Grundbegriffe der Metaphysik. Welt-Endlichkeit-Einsamkeit. Frankfurt: Klosterman.

Kant, I.(1964) Anthropologie im pragmatischer Hinsicht. In Kant Werke (Bd. 6). Frankfurt: Insel Verlag.

Koselleck, R. (2000). Zeitschichten. Frankfurt: Suhrkamp.

Koselleck, R. (2012). Bildung ist weder Ausbildung noch Einbiludung, In H. Hastedt (Ed.), Was ist Bildung. Eine Textantologie. Reklam: Stuttgart.

Löffler, O. (2014). Verteilte Aufmerksamkeit. Berlin: Diaphanes.
Mas, S.(2010). La Grecia de Wilhelm von Humboldt o Ilustración y Clasicismo, In W. Humboldt, W. Historia de la decadencia y ocaso de los Estados libres griegos. Madrid: Plaza y Valdés.

Montaigne, M.(2007). Los ensayos. Barcelona, Acantilado.

Nietzsche, F. (1988). Menschlisches, Allzumenschliches I. In F. Nietzsche, Kritische Gesamtausgabe (Bd. 2). Berlin: De Gruyter.

Pascal, B. (1981). Pensamientos. Madrid: Alianza Editorial. Quevedo, F. (1996). Poesía original completa. Barcelona: Planeta.

Rosa, H. (2016). Alienación y aceleración. Buenos Aires: Katz.

Steiner, G. (1997). El lector infrecuente. In G. Steiner, G. Pasión intacta (pp. 19-45). Madrid: Siruela.

Weil, S. (1988). Réflexions sur le bon usage des études scolaires. In S. Weil, Oeuvres Completes (Vol. IV). Paris: Gallimard.

\section{António Gómez Ramos}

Doctor en Filosofía y Letras, sección filosofía, por la Universidad Autónoma de Madrid, España. Licenciado en Filosofía y Letras, sección Filosofía, por la Universidad Autónoma de Madrid. Estudios finalizados en 1987, en la especialidad de Lógica y Teoría de la Ciencia. Grado obtenido en 1991, con la calificación de Sobresaliente y premio extraordinario. (Memoria de licenciatura: Hermenéutica e Idealidad del texto). Profesor Titular de Filosofía en la Universidad Carlos III de Madrid, Departamento de Humanidades: Filosofía, Lenguaje y Literatura.

\section{Dirección}

António Gomes Ramos

Universidad Carlos III

Calle Madrid, 126, 28903

Getafe, Madrid, España 